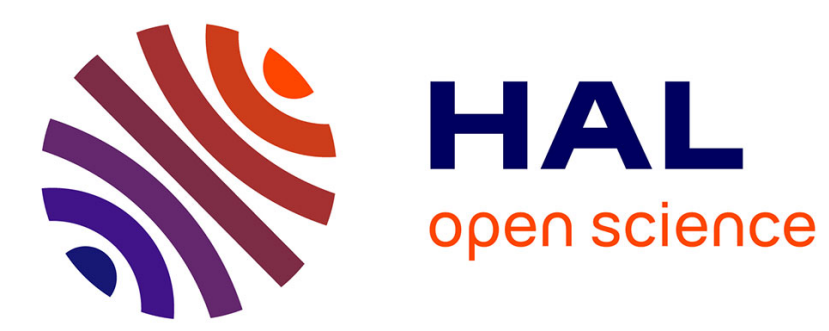

\title{
VELab: A VIRTUAL LAB FOR ELECTRONICS VIRTUAL EXPERIMENTS
}

Jean-Pierre Gerval, Yann Le Ru

\section{To cite this version:}

Jean-Pierre Gerval, Yann Le Ru. VELab: A VIRTUAL LAB FOR ELECTRONICS VIRTUAL EXPERIMENTS. Advanced Technology for Learning, 2006, 3 (2), pp.82-88. hal-02998975

\section{HAL Id: hal-02998975 \\ https://hal.science/hal-02998975}

Submitted on 10 Nov 2020

HAL is a multi-disciplinary open access archive for the deposit and dissemination of scientific research documents, whether they are published or not. The documents may come from teaching and research institutions in France or abroad, or from public or private research centers.
L'archive ouverte pluridisciplinaire HAL, est destinée au dépôt et à la diffusion de documents scientifiques de niveau recherche, publiés ou non, émanant des établissements d'enseignement et de recherche français ou étrangers, des laboratoires publics ou privés.

$$
\text { Copyright }
$$




\title{
VELab: A VIRTUAL LAB FOR ELECTRONICS VIRTUAL EXPERIMENTS
}

\author{
J-P. Gerval, Y. Le Ru*
}

\begin{abstract}
This paper sets out a virtual reality application dedicated to electronics virtual experiments: circuit design and simulation. The virtual environment offers virtual components (resistors, capacitors, inductors, diodes, transistors and operational amplifiers) and virtual electronics equipments (generators and oscilloscopes) They are described in a standard Virtual Reality Modeling Language (VRML) format. Students can choose components and build a circuit. A remote simulation of the circuit is achieved using the SPICE program, which is a general-purpose circuit simulation program for non-linear dc, non-linear transient, and linear ac analyses. Simulation results are displayed on virtual electronics equipments, which are involved into the simulation. The implementation is based on VRML and Java as languages and Cortona VRML plug-in from ParallelGraphics. It is available through the Internet at the following URL: http://intranet.iseb.fr:85/
\end{abstract}

Key Words: Virtual Environments, Virtual Reality Modeling Language, Java, Electronics Simulation, Electronics Virtual Experiments, Web-based Training.

\section{Introduction}

Until now, we have nearly 200 students using laptops for different purposes. By the end of June 2004, we made a survey in order to collect information on students' point of view about their laptop and our e-Campus.

One of the questions was: "What are your main uses of your laptop?" Answers are shown in Fig. 1.

This survey points out that schoolwork is the first use (23.37\%). But the practice of games $(21.41 \%)$ is very close to schoolwork. Only a few students are using their computer for software development $(3.85 \%)$. This is due to the fact that our school is mainly a Graduate School of Electronics.

Commercial games have created a form of learning that students are very familiar with [1]. Game based learning is a nice way to involve students in the process of learning.

According to these facts, we have decided to pay interest in the development of game-like pedagogical tools in order to improve creativity and teamwork.

\footnotetext{
* ISEN Brest - Department of Computer Sciences

20 rue Cuirassé Bretagne - CS 42807

29228 Brest Cedex 2 - France

Email : \{jean-pierre.gerval, yann.le-ru@isen.fr\}
}

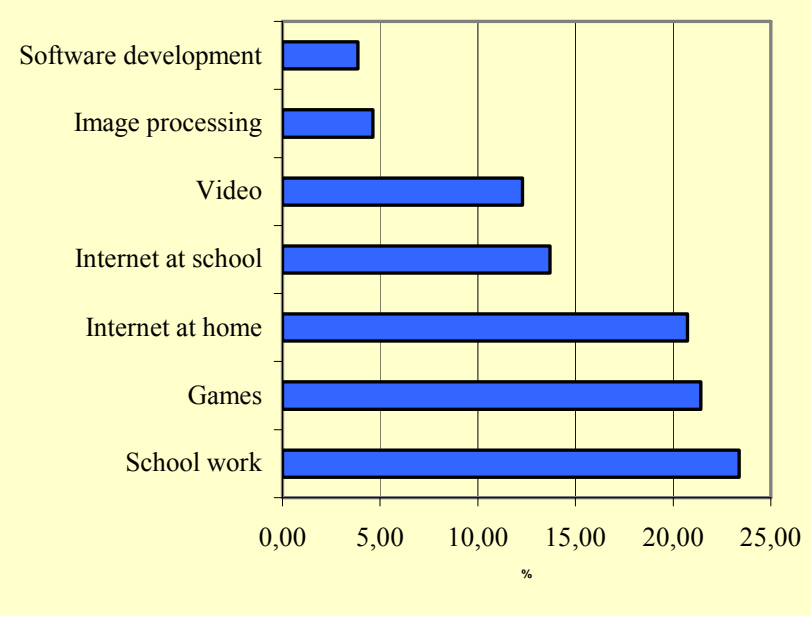

Fig. 1. Student's laptop uses (\%)

The main goal of our project is to develop a virtual world that a group of students will share in order to achieve some electronics virtual experiments together.

Such a virtual world would implement:

- Virtual components and virtual electronics equipments,

- Intelligent pedagogical agents dedicated to the monitoring of students activities.

In this paper, we focus on the development of the virtual world dedicated to electronics experiments: circuit design and simulation. This development is an early first step toward a multi-user distributed application that would involve a group of students into a common task.

The first part of the paper deals with a brief survey of existing pedagogical materials dedicated to electronics simulations. In the second part we describe the virtual world that has been developed: virtual components and virtual electronics equipments. The third part of the paper gives details about some technical aspects of our development and especially the simulation, which is based on the SPICE program. 


\section{Quick survey}

A quick survey on existing pedagogical materials points out that the main tools dedicated to the training in electronics are generally $2 \mathrm{D}$ software.

Two examples of projects, which are providing such pedagogical materials, are:

- INEIT-MUCON [2] - Innovation for Education in Information Technology through Multimedia and Communication Networks (1996-2000)

- THEIERE [3] - Thematic Harmonisation in Electrical and Information EngineeRing in Europe (2000-2003)

They are targeting families of applications. They are not really "game-like". They rarely enable teamwork. Sometimes, they have multimedia components and fit with distance learning requirements but generally there is a lack of user interactivity compare to virtual reality applications.

A special attention should be paid to EDISON [4]. It offers 3D photorealistic components and a pleasant way to learn electricity and basic electronics. But this software runs on one computer for one user. It is not Web-Based. That means that multiple clients cannot share the same application through the Web.

In other cases, the target is to share and use lab equipments through the network, for examples:

- Microelectronics WebLab [5]

- Virtual Laboratories In Electronic Engineering Education [6]

None of these applications provide immersive environments where students are involved as actors in order to design and simulate electronics circuits.

\section{Virtual world description}

The implementation of the virtual world is based on VRML (Virtual Reality Modeling Language) [7]. Users may view 3D contents with a Web Browser and a VRML plug-in. The actual implementation is using Cortona VRML plug-in from ParallelGraphics.

In VELab, the virtual world is populated by virtual entities: components and equipments that correspond to real world objects. These entities are able to perceive, decide and react according to their profile, internal structure and tasks.

The interactions between users and entities are of cause-effect type. A stimulus may be emitted to the virtual world according to a change of an entity's state. Our entities are autonomous because they can adapt to the dynamic environment.

\subsection{Virtual components}

Until now, we have implemented six different types of components, which are passive (Fig. 2.) components:

- Resistors,

- Capacitors,

- Inductors,

And active (Fig. 3.) components:

- Diodes,

- Transistors,

- Operational amplifiers.

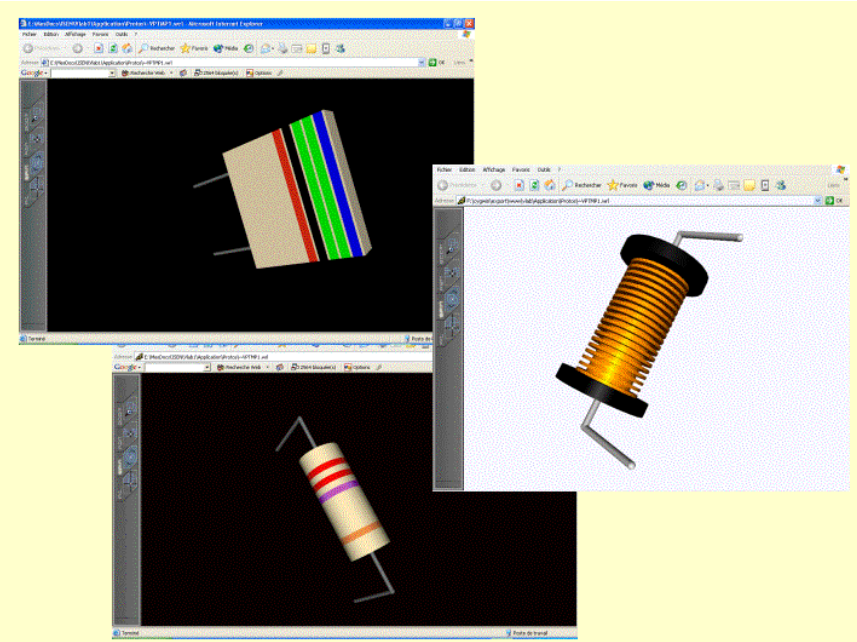

Fig. 2. Passive components

Students can choose a value for resistors or capacitors by selecting the right colours on the components according to colour codes.

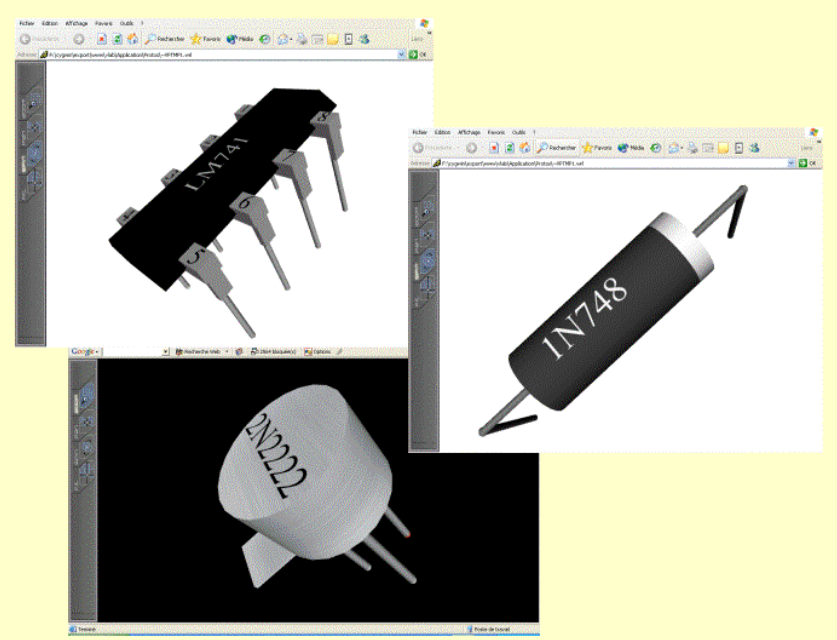

Fig. 3. Active components

Concerning the other components, a menu has been implemented that enables students to choose a value (Fig. 4.) 


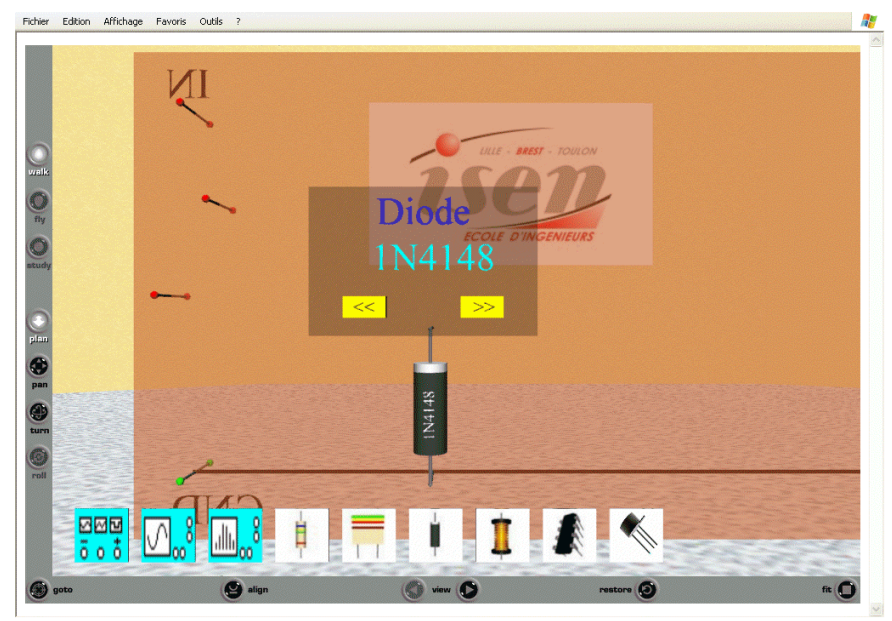

Fig. 4. Choose a component value

For example, if a student wants to fix a value for a diode, he has to click on the diode white line in order to make the menu appear (or disappear). A text appears according to the current value of the component. The student can change this value by clicking on the yellow sensors.

Five types of diodes are available:

- 1 N748 (Zener - 3,9 volts)

- 1 N754 (Zener - 6,8 volts)

- $\quad 1 N 757$ (Zener - 9,1 volts)

- $1 \mathrm{~N} 4001$

- $1 \mathrm{~N} 4148$

Four types of transistors:

- $2 \mathrm{~N} 2222$

- $2 \mathrm{~N} 2907$

- $2 \mathrm{~N} 5416$

- $2 \mathrm{~N} 3440$

And one type of operational amplifier:

- LM741

\subsection{Designing a circuit}

Components are inserted into the virtual world when students click on the corresponding icon (Fig. 5.).

Students can move (or rotate) components by means of virtual axis (Fig. 6.) that represent the directions of the movement.

After they have put components on the virtual PCB (Printed Circuit Board), students can build their circuit by clicking on components' pins behind the virtual PCB (Fig. 7.).

A link is created in the virtual world. A black line is drawn between components' pin. This line symbolizes a connection between two components.

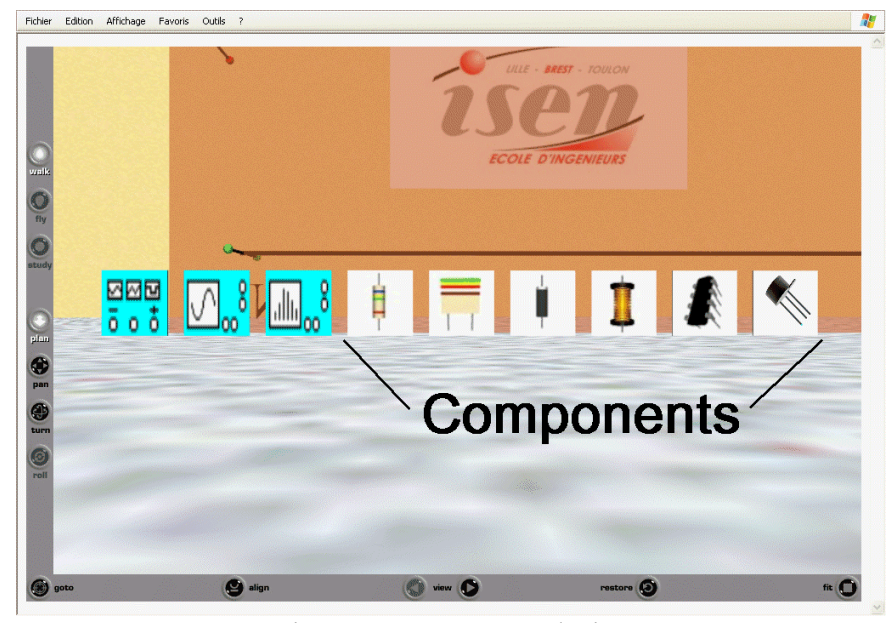

Fig. 5. Component choice

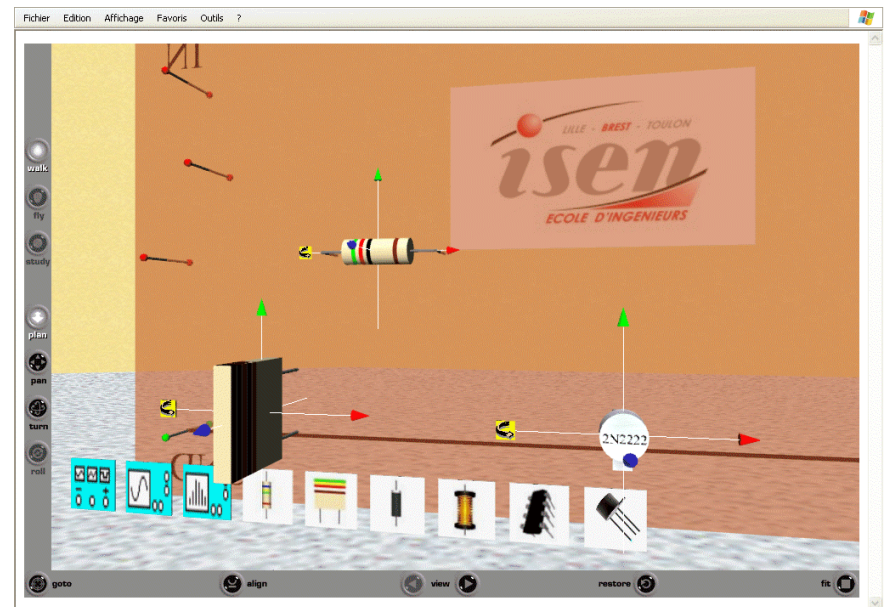

Fig. 6 Moving components

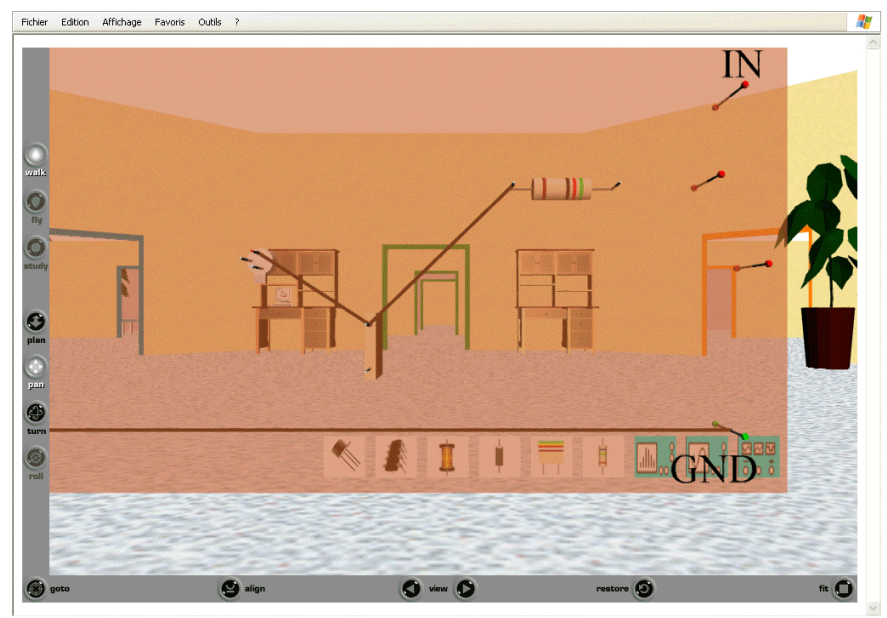

Fig. 7. Drawing the circuit

Such a link can't be deleted. That means that the components have been virtually welded on the virtual PCB. Components can't be moved anymore. As a result, students must take time to think about the work that they have to achieve. 


\subsection{Virtual electronics equipments and simulation}

Two types of virtual electronics equipments are available today: generators and oscilloscopes. A spectral analyser is under development and will be soon available.

Equipments are inserted into the virtual world when students make their choice by clicking on the relevant blue icon (Fig. 5.).

Generators (Fig. 8.) enable students to set up a signal in terms of frequency, voltage and waveform. This signal will be applied to the circuit on the inputs selected by the student.

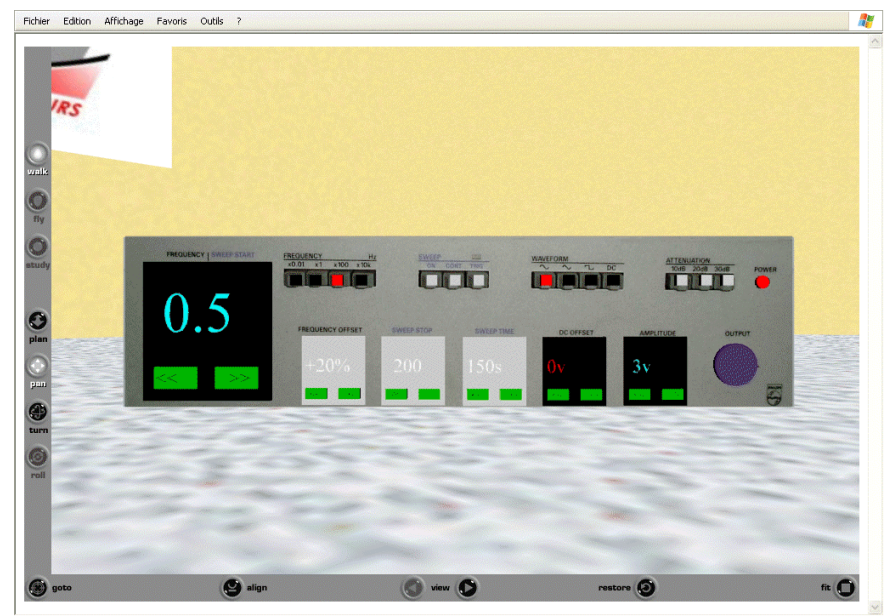

Fig. 8. Generator

A new link is created into the virtual world when a student clicks on the output of a generator and a components' pin.

Oscilloscopes (Fig. 9.) enable students to view circuits' outputs. That is to say: "simulation results". For each oscilloscope two channels are available. Students can adjust voltage and/or time scale.

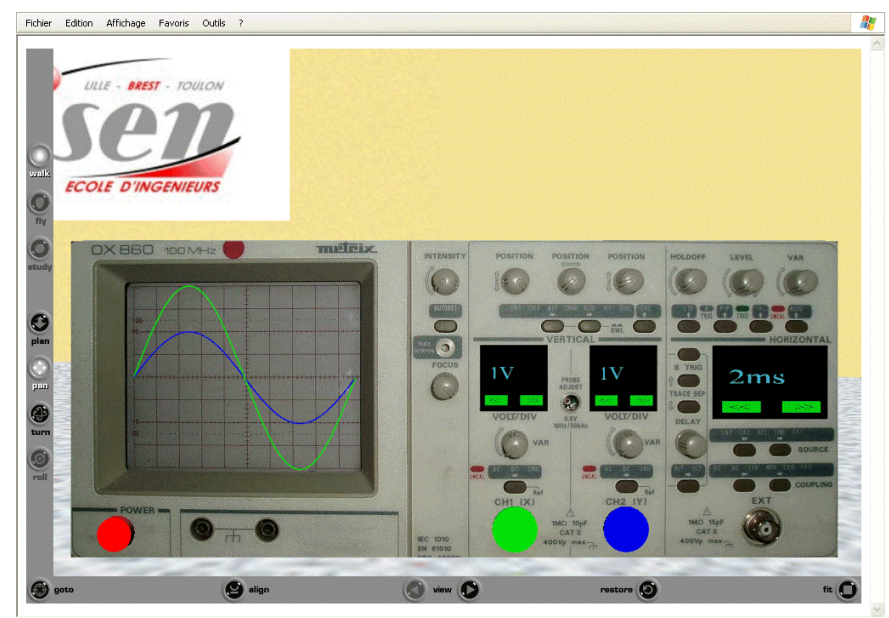

Fig. 9. Oscilloscope
Once more, a link is created into the virtual world when a student clicks on a channel input and a components' pin.

We have introduced special components (pads) on the virtual $\mathrm{PCB}$ in order to make easier connections between virtual electronics equipments and the circuit.

An arrow is drawn on the pad or the components' pin, which was selected by the student. This arrow symbolizes a connection between the equipment and the circuit. Each arrow holds a generator identifier or an oscilloscope and channel identifier.

By default, all equipments are virtually connected to the ground. On the one hand, students will not have to care about these links. On the other hand, we will not have to insert special drawings to symbolize ground into the virtual world.

\subsection{Managing files}

A basic file manager has been implemented in order to save on going work (Fig. 10.).

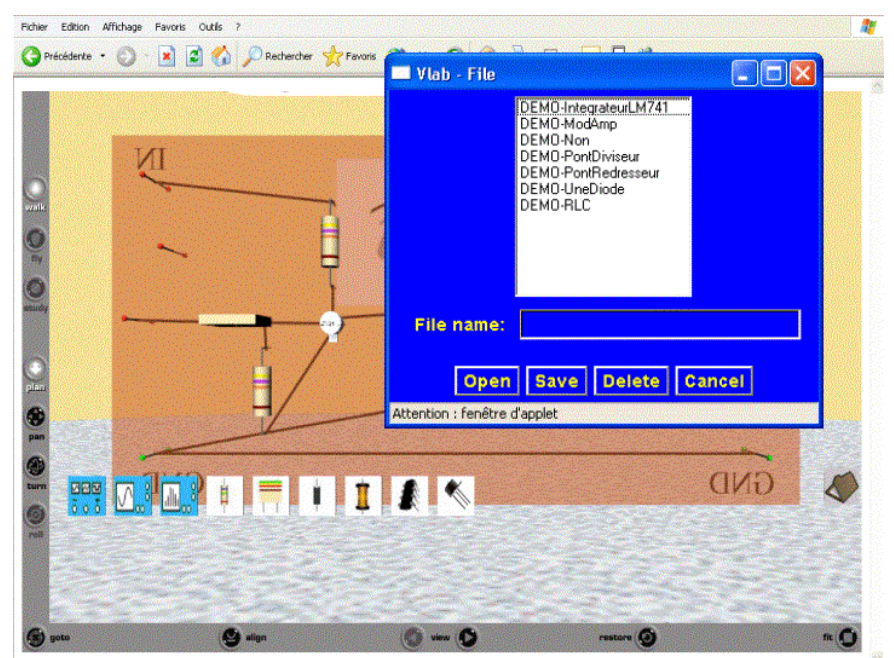

Fig. 10. File manager interface

Each student (or user) can set up an account on the server. A directory is created so that links, components values and locations might be stored in a file. These data can be loaded at anytime.

We advise students to use this functionality as often as possible according to the fact that virtual links between components can't be deleted.

When a new file is uploaded, all links from the circuit to generators and oscilloscopes are removed. Simulation results are erased from oscilloscope screen. 
Simulation results are also erased when students change:

- Generators or oscilloscopes settings,

- Values of components that had been virtually welded on the virtual $\mathrm{PCB}$.

These above-mentioned facts point out that we have to make our virtual world consistent with the states of equipments and components.

\section{Technical point of view}

The Virtual Lab. software architecture (Fig. 11.) on client side implements a VRML (Virtual Reality Modeling Language) application and two Java modules.

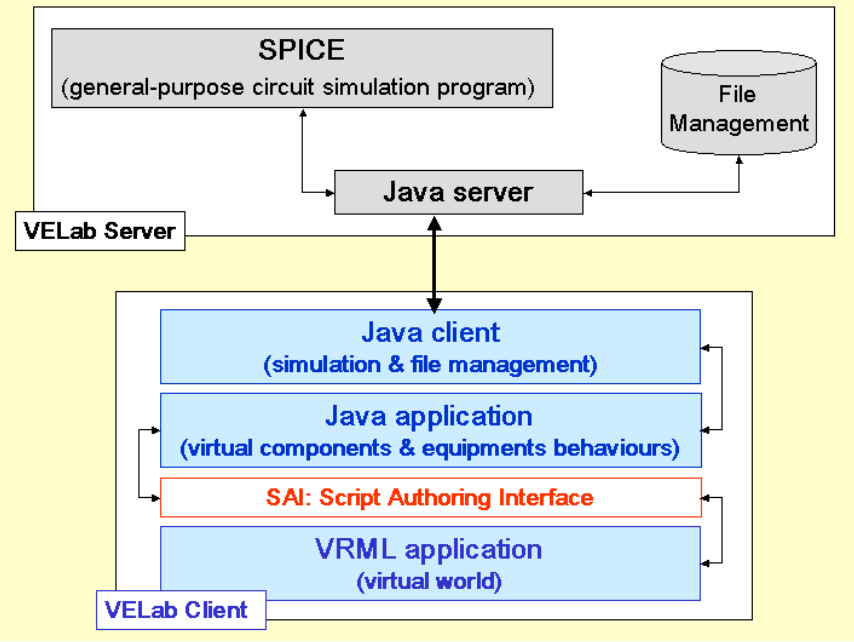

Fig. 11. Virtual Lab. software architecture

The VRML application describes 3D virtual world and prototypes of each components and equipments. Local behaviours such as clicks on icons, components displacements, etc. are managed locally by this VRML application. Java Script codes are embedded into the VRML application for this purpose.

The first Java module (Java application) manages virtual components' values and computes data for simulation. Java classes (Fig. 12.) manage user interactions within the virtual world according to VRML specifications: Script Authoring Interface [8].

The second Java module (Java client) enables information exchange with the Server through the Internet:

- File management: save or upload data,

- Simulation: send data to the server and receive simulation results.

On the server side (Java server), threads are launched in order to serve clients requests:

- File is stored, deleted or transferred,
- SPICE is launched with simulation data that were previously received and results are sent back to the client.

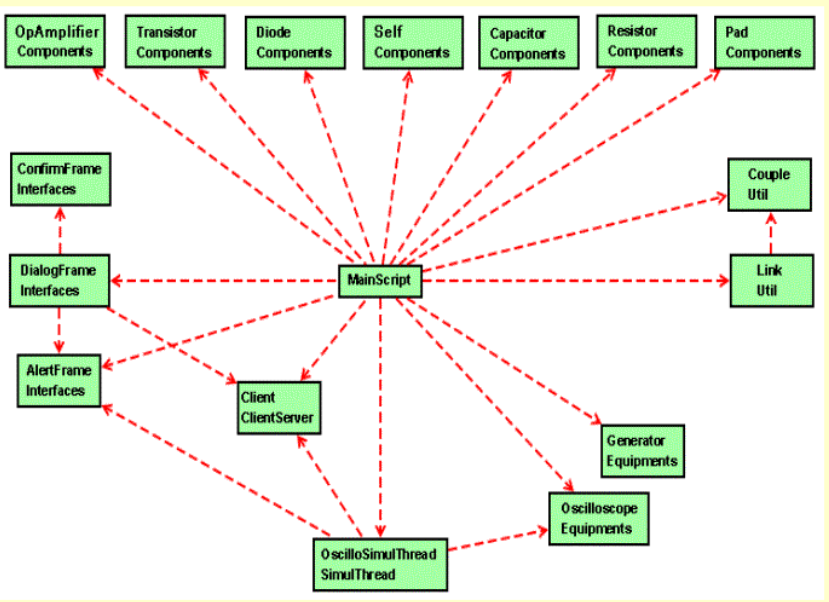

Fig. 12. Virtual Lab. Java objects and packages

This client-server architecture implements sockets under TCPIP. A basic protocol has been established in order to enable the server to recognise clients request.

\subsection{From design to simulation: topology}

When a student clicks on components pins in order to draw the circuit we create a link $\mathrm{L}_{\mathrm{i}}$ by means of a set of two couple:

Where:

$$
\mathrm{L}_{\mathrm{i}}=\left\{\left(\mathrm{N}_{\alpha}, X\right),\left(\mathrm{N}_{\beta}, Y\right)\right\}
$$

\section{$\mathrm{N}_{\alpha}$ and $\mathrm{N}_{\beta}$ are components name} $X$ and $Y$ describes components pin

And:

$$
X, Y \in \mathrm{N}^{*}
$$

All these links give a representation of the circuit topology.

For example, according to the circuit (Fig. 13.) that represents a basic bridge of two resistors, we have:

- Resistor $\mathrm{R}_{0}$ with couples $\left(\mathrm{R}_{0}, 1\right)$ and $\left(\mathrm{R}_{0}, 2\right)$ associated to resistor's pins,

- Resistor $\mathrm{R}_{1}$ with couples $\left(\mathrm{R}_{1}, 1\right)$ and $\left(\mathrm{R}_{1}, 2\right)$ associated to resistor's pins,

- Generator $\mathrm{V}_{1}$ with couples $\left(\mathrm{V}_{1}, 1\right)$ and $\left(\mathrm{V}_{1}, 2\right)$ respectively associated to generator ground and output,

- Oscilloscope $\mathrm{O}_{1}$ with couples $\left(\mathrm{O}_{1}, 1\right)\left(\mathrm{O}_{1}, 2\right)$ and $\left(\mathrm{O}_{1}, 3\right)$ respectively associated to oscilloscope channels (one and two) and ground,

- Input pad with couple $\left(\mathrm{P}_{5}, 1\right)$

- Output pads with couples $\left(\mathrm{P}_{1}, 1\right)$ and $\left(\mathrm{P}_{2}, 1\right)$

- Ground pads with couples $\left(\mathrm{P}_{3}, 1\right)$ and $\left(\mathrm{P}_{7}, 1\right)$ 


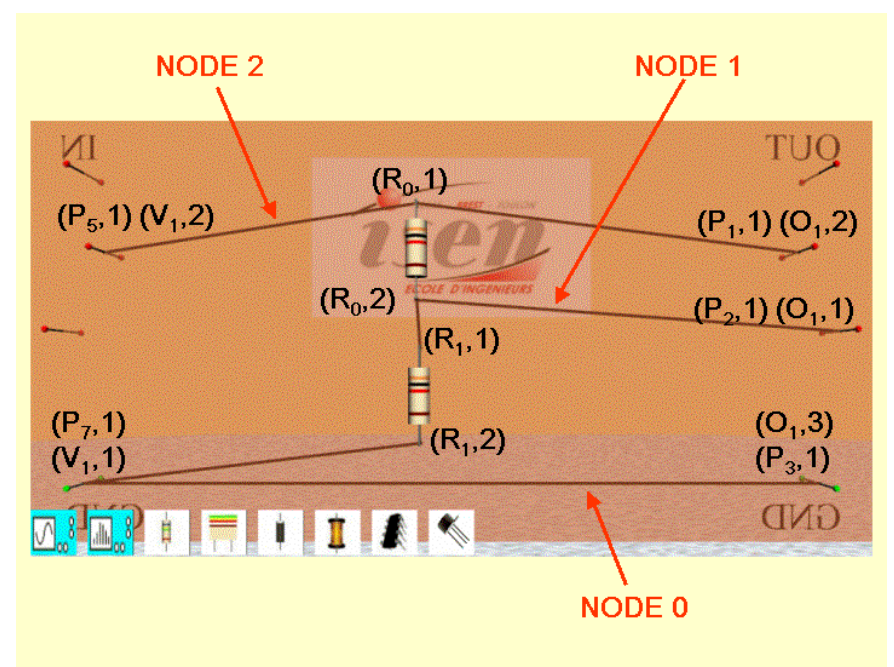

Fig. 13. Circuit example

When the student was drawing the circuit, we had created the following links:

$$
\begin{aligned}
& \mathrm{L}_{0}=\left\{\left(\mathrm{P}_{7}, 1\right),\left(\mathrm{P}_{3}, 1\right)\right\} \\
& \mathrm{L}_{1}=\left\{\left(\mathrm{V}_{1}, 1\right),\left(\mathrm{P}_{7}, 1\right)\right\} \\
& \mathrm{L}_{2}=\left\{\left(\mathrm{O}_{1}, 3\right),\left(\mathrm{P}_{3}, 1\right)\right\} \\
& \mathrm{L}_{3}=\left\{\left(\mathrm{P}_{5}, 1\right),\left(\mathrm{V}_{1}, 2\right)\right\} \\
& \mathrm{L}_{4}=\left\{\left(\mathrm{P}_{5}, 1\right),\left(\mathrm{R}_{0}, 1\right)\right\} \\
& \mathrm{L}_{5}=\left\{\left(\mathrm{R}_{0}, 1\right),\left(\mathrm{P}_{1}, 1\right)\right\} \\
& \mathrm{L}_{6}=\left\{\left(\mathrm{P}_{1}, 1\right),\left(\mathrm{O}_{1}, 2\right)\right\} \\
& \mathrm{L}_{7}=\left\{\left(\mathrm{R}_{0}, 2\right),\left(\mathrm{R}_{1}, 1\right)\right\} \\
& \mathrm{L}_{8}=\left\{\left(\mathrm{R}_{0}, 2\right),\left(\mathrm{P}_{2}, 1\right)\right\} \\
& \mathrm{L}_{9}=\left\{\left(\mathrm{P}_{2}, 1\right),\left(\mathrm{O}_{1}, 1\right)\right\} \\
& \mathrm{L}_{10}=\left\{\left(\mathrm{R}_{1}, 2\right),\left(\mathrm{P}_{7}, 1\right)\right\}
\end{aligned}
$$

Links $\mathrm{L}_{0}, \mathrm{~L}_{1}$ and $\mathrm{L}_{2}$ are automatically created when the virtual world is loaded into the client browser. These links correspond to the ground.

The next step, prior to simulation, is to compute equipotential nodes. An equipotential node is a set of couples where all pins are sharing the same connection.

The computation of equipotential nodes implements a transitivity relation between links.

For example, $\mathrm{L}_{0}$ and $\mathrm{L}_{1}$ :

$$
\begin{aligned}
& \mathrm{L}_{0}=\left\{\left(\mathrm{P}_{7}, 1\right),\left(\mathrm{P}_{3}, 1\right)\right\} \\
& \mathrm{L}_{1}=\left\{\left(\mathrm{V}_{1}, 1\right),\left(\mathrm{P}_{7}, 1\right)\right\}
\end{aligned}
$$

Are sharing a common connection $\left(\mathrm{P}_{7}, 1\right)$ that means that couples $\left(\mathrm{P}_{7}, 1\right),\left(\mathrm{P}_{3}, 1\right)$ and $\left(\mathrm{V}_{1}, 1\right)$ belong to the same node.

In the framework of our example, the computation of equipotential nodes gives three nodes as a result. Finally, we obtain the following set of nodes:

$$
\begin{aligned}
& \operatorname{NODE}_{0}=\left\{\left(\mathrm{P}_{3}, 1\right),\left(\mathrm{P}_{7}, 1\right),\left(\mathrm{V}_{1}, 1\right),\left(\mathrm{O}_{1}, 3\right),\left(\mathrm{R}_{1}, 2\right)\right\} \\
& \operatorname{NODE}_{1}=\left\{\left(\mathrm{R}_{1}, 1\right),\left(\mathrm{R}_{0}, 2\right),\left(\mathrm{P}_{2}, 1\right),\left(\mathrm{O}_{1}, 1\right)\right\} \\
& \operatorname{NODE}_{2}=\left\{\left(\mathrm{R}_{0}, 1\right),\left(\mathrm{P}_{1}, 1\right),\left(\mathrm{P}_{5}, 1\right),\left(\mathrm{O}_{1}, 2\right),\left(\mathrm{V}_{1}, 2\right)\right\}
\end{aligned}
$$

Where $\mathrm{P}_{i}, \mathrm{~V}_{\mathrm{i}}, \mathrm{O}_{\mathrm{i}}$ and $\mathrm{R}_{\mathrm{i}}$ respectively represent Pads, Generators, Oscilloscopes and Resistors. This set of nodes is used to create the netlist of the circuit.

\subsection{From simulation to results}

The simulation is implemented by means of the SPICE software [9]. SPICE is a general-purpose circuit simulation program for non-linear dc, non-linear transient, and linear ac analyses. In the context of this project simulation runs on a server according to clients' requests.

SPICE has already been used remotely through the web [10] [11] but in our case the virtual environment acts as an authoring tool generating a description of the circuit being simulated. This description is written in SPICE 'language'.

Simulation results are displayed on virtual electronics equipments that are involved into the simulation.

For example, when a student decides to run a simulation of the previous circuit (Fig. 13.) a text file is generated according to SPICE syntax:

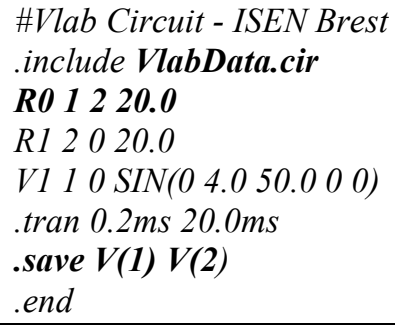

This file contains the netlist of the circuit and the main directives for the simulation that is required from SPICE.

For example:

- $R 01220.0$ means that R0 is connected between nodes one and two and resistance is equal to 20 ohms;

- .save $V(1) V(2)$ requires a voltage computation between the ground and, respectively, nodes one and two.

The SPICE text file includes a reference to a special file VlabData.cir that contains active components models definitions. This file is located on the server. 
For example:

$$
\begin{aligned}
& \text {. model m2N2222 npn is }=19 f \text { bf }=150 \text { vaf }=100 \\
& i k f=.18 \text { ise }=50 p \text { ne }=2.5 \mathrm{br}=7.5 \text { var }=6.4 \mathrm{ikr}=12 \mathrm{~m} \\
& i s c=8.7 p n c=1.2 \mathrm{rb}=50 \mathrm{re}=0.4 \mathrm{rc}=0.4 \mathrm{cje}=26 \mathrm{p} \\
& t f=0.5 n c j c=11 p \text { tr }=7 n x t b=1.5 \mathrm{kf}=0.032 \mathrm{f} a f=1
\end{aligned}
$$

Describes a Bipolar Junction Transistors named m2N2222. According to SPICE syntax, model names must start with an alphabetical character.

This VlabData.cir file acts as a sort of library in which we can add new models of components. Today, thanks to the Internet, it is easy to get spice macromodels directly from manufacturers. For example National Semiconductor provides SPICE macromodels for its amplifier products [12].

The SPICE text file is sent from the client to the server. The server runs the SPICE program. Results are written in a text file and sent back to the client. According to our example, the client will receive the following data:

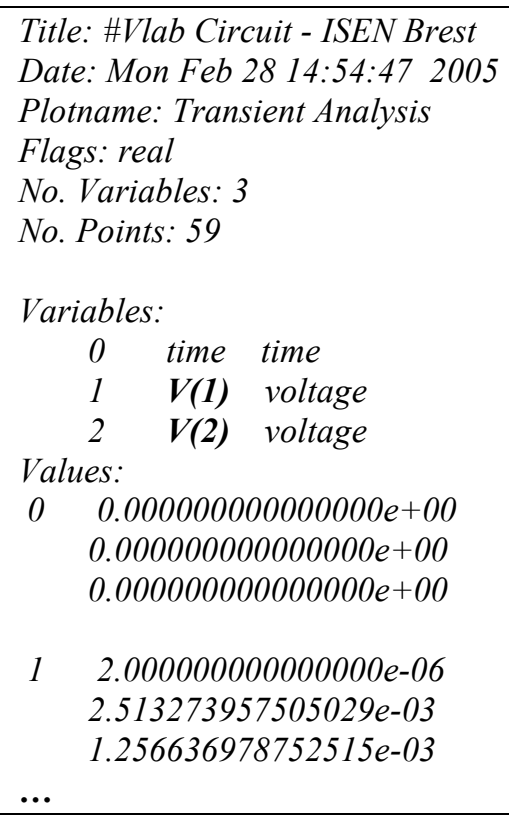

This is a set of values that describes temporal evolutions of signals $\mathbf{V ( 1 )}$ and $\mathbf{V ( 2 )}$.

On client side, values are extracted from the text file. They are used to draw the result on the screen of the virtual oscilloscope according to voltage and time scale (Fig. 9.).

As time scale may be different from one oscilloscope to another, we have decided to run as much simulation as we have virtual equipments involved in the experiment.
According to a classical client-server architecture there is one thread running per equipment involved into the simulation (Fig. 12.).

\section{Conclusions and future works}

The target of this first prototype was to demonstrate the feasibility to plug an external simulation program such as SPICE to a virtual world dedicated to electronics circuit simulations.

This first prototype was available on the intranet of our school by the middle of July 2005. At the end of August, close to thirty students visited this new pedagogical resource. That was especially surprising, because there were no special advertisement and also it was holiday time. That proves that students were already curious and interested in this new kind of pedagogical tool.

First experiments with students point out that it is necessary to change the behaviour of the user interface in order to run a simulation. For example, if generators or components values are changed after a simulation has been achieved, the drawing on the screen of the oscilloscope is erased. It would be better and much more realistic to request a simulation from the server each time a value is changed in the virtual world and then to update automatically the screen of the oscilloscope.

Also in order to increase the realism of this virtual world dedicated to virtual experiments, it should be much more pedagogical to generate explosions with sound and smoke when currents or voltages are out of range. It should be much more realistic to take into account components specifications at simulation time.

In the immediate future, we will introduce new components such as: LEDs, MOS transistors, logic gates, flip-flops, integrated circuits and new virtual electronics equipments such as a spectral analyser. This will enable us to enhance types of circuits that would be designed.

A special version of VELab should be developed for Power Electronics. In this special case, students should be able to experiments, without any risk, electronics circuits that involve high voltages and high currents.

Another evolution of VELab would be to introduce failures into the circuit such as:

- Bad welding,

- Non calibrated oscilloscope,

- Bad grounds etc.

In this case, the target for the student would be to discover the failure in order to repair the circuit. 
We are also working on a distributed version of our Virtual Lab. This distributed implementation will be based on DeepMatrix [13] as environment server. Such an implementation has already been developed in a previous project [14] [15] dedicated to primary schools children. This distributed version will enable teamwork and will also integrate pedagogical agents.

The virtual world will be shared by a group of students. The virtual world offers different rooms where each student will have to perform a task. Each of them will have to design a part of a circuit, for example an oscillator, a filter and amplifier. They will have to cooperate according to the fact that they will have to interconnect their own realisations into one main circuit, for example a transmitter.

Another ongoing work lies in the development of pedagogical agents and especially tutors behaviour as a complement to technical agents: components and equipments. Students should be treated as actors [16] and one, or more, specialized virtual tutor should control and evaluate students' work.

\section{References}

[1] J. Foreman, Game Based Learning, EDUCAUSE review, September/October 2004

[2] http://www.eaeeie.org/ineit-mucon/

[3] http://www.eaeeie.org/theiere/

[4] http://www.tina.com/

[5] http://icampus.mit.edu/iLabs/

[6] Vicent M. Rodrigo Peñarrocha, Miguel Ferrando Bataller, Mariano Baquero Escudero, Alejandro Valero Nogueira, Virtual Laboratories In Electronic Engineering Education, International Conference on Network Universities and E-learning, Valencia, Spain, 8-9 May, 2003

[7] VRML Standard Version 2.0, ISO/IEC CD 14772, 1996, http://apia.u-strasbg.fr/vrml/ressources/specs/spec/

[8] Martin McCarthy, Alligator Descates, Reality Architecture - Building $3 d$ worlds with Java and VRML, Prentice Hall Europe, 1998, ISBN 0-13748625-1.

[9] http://bwrc.eecs.berkeley.edu/Classes/IcBook/SPICE/

[10] S. Solaimalai, P. Hicks, Techniques for embedding circuit simulations into electronics design courseware, International Conference on Engineering Education, Oslo, Norway, August 6 - 10, 2001

[11] B. M. Wilamowski, A. Malinowski, and J. Regnier, SPICE based Circuit Analysis using Web Pages, ASEE 2000 Annual Conference, St. Louis, MO, June 18 to 2, 2000, CD-ROM session 2520.

[12] http://www.national.com/appinfo/amps/0,2175,815,00.html

[13] Gerhard Reitmayr, Shane Carroll, Andrew Reitmeyer, Michael G. Wagner, DeepMatrix - An Open Technology Based Virtual Environment System, White Paper, October 30, 1998, http://www.geometrek.com/developers/

[14] J.P. Gerval, M. Popovici, M. Ramdani, O. El Kalai, V. Boskoff, J. Tisseau, Virtual Environments for Children, IASTED International Conference, Computers and Advanced Technology in Education, CATE 2002, Cancun, Mexico, May 20-22, 2002
[15] Popovici D.M., Gerval J.P., Chevallier P., Tisseau J., Serbatani L.D., Gueguen P., Educative distributed virtual environments for children, Special issue "Cyberworlds and education" of The International Journal of Distance Education Technologies, Vol. 2, No. 4, Oct-Dec 2004

[16] M. Popovici, D. Serbatani, J.P. Gerval, Virtual Perception Based Agents in Virtual Theater, Technologies for Interactive Digital Storytelling and Entertainment, TIDSE 2003, Darmstadt, Germany, march 24-26, 2003

\section{Biographies}

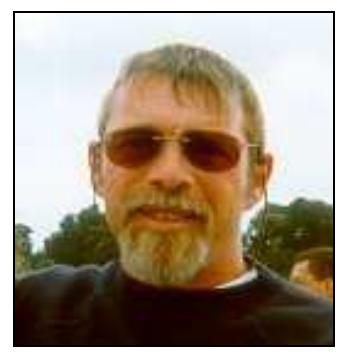

Jean-Pierre Gerval obtained his Doctorate in Automation from the University of Valenciennes in France, 1987. He has been Project Manager at the "Institut d'Informatique Industrielle" (3xi) in Brest from 1988 to 2003 and Associate Professor of Computer Sciences at the "Ecole Nationale d'Ingénieurs de Brest" (ENIB) from 1993 to 2003. He is currently head of the Computer Sciences Department at the "Institut Supérieur de l'Electronique et du Numérique" (ISEN) in Brest. His research interests are in Distributed Virtual Reality, e-Learning and Virtual Environments especially dedicated to pedagogical applications.

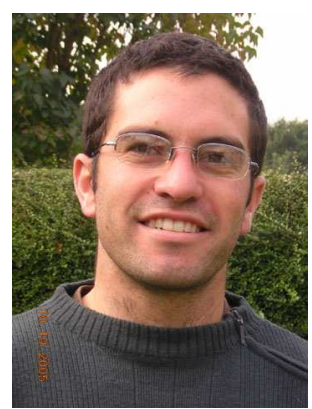

Yann Le $R u$ received his Graduate Engineering Degree from the E.N.S.T. Bretagne in France (Graduate School of Telecommunication Engineering), 2001. He is currently Network Administrator and Lecturer at the "Institut Supérieur de l'Electronique et du Numérique" (ISEN) in Brest. 